\title{
CT Scan Guided Trans-Sternal Approach for Anterior Mediastinal Mass Biopsy
}

\author{
Vishal N. Bakare ${ }^{1}$, Shubhasish Pattnaik ${ }^{2}$ \\ ${ }^{1}$ Faculty, Dr. D.Y.Patil Medical College, Hospital and Research Hospital, Pimpri, Maharashtra, India \\ ${ }^{2}$ Dr. D.Y.Patil Medical College, Hospital and Research Hospital, Pimpri, Maharashtra, India
}

Corresponding Author: Vishal N. Bakare

\begin{abstract}
Anterior mediastinal lesions which are directly posterior to the sternum and have no significant parasternal component are difficult to approach for biopsy. Very few cases of CT-guided transsternal mediastinal mass biopsy have been reported in the literature. We report two cases of CT guided trans-sternal mediastinal mass biopsy to highlight the importance of this technique.
\end{abstract}

Keywords: CT scan, Mediastinal mass, Transsternal approach, Biopsy

\section{INTRODUCTION}

Anterior mediastinal lesions which are directly posterior to the sternum and have no significant parasternal component are difficult to approach for biopsy. Very few cases of CT-guided transsternal mediastinal mass biopsy have been reported in the literature. We report two cases of CT guided transsternal mediastinal mass biopsy to highlight the importance of this technique.

\section{CASE REPORT}

Case 1: 66 years old gentleman presented with on \& off chest pain and swelling over face since 2 weeks. He was clinically examined \& investigated with routine blood tests and X-ray of chest. X-ray chest revealed bilateral pleural effusion (Left $>$ right). Ultrasound guided aspiration of left sided pleural effusion was done which revealed positive cytology for malignant cells. PET scan was done for further evaluation. It revealed metabolically active heterogeneously enhancing soft tissue lesion in anterior mediastinum (Figure 1) along with multiple mediastinal, axillary enlarged lymph nodes. Also, there were multiple metabolically active bilateral lung nodules along with skeletal lesions (Figure 2). So the overall picture was likely to be of gross metastatic disease. For histopathological diagnosis, CT guided anterior mediastinal biopsy was planned. On pre procedural CT scan, the lesion was completely retro-sternal with no para-sternal extension. Hence, we decided to go for trans-sternal oblique approach for the biopsy in order to avoid injury to great vessels (Figure 3). Multiple tissue cores were obtained successfully from the lesion with no intra and post procedural complications. The pathology report was suggestive of metastatic deposits of mucinous adenocarcinoma with signet cell morphology. The patient is now being managed on chemotherapy for the metastatic disease.

Case 2: 23 years female patient presented with complaints of neck swelling, breathlessness and weight loss since 1 month. CT scan of the Thorax was done which revealed soft tissue mass involving superior and anterior mediastinum (Figure 4). It was closely abutting the great vessels and pericardium. As there was no significant parasternal component, CT scan guided trans-sternal biopsy was done and adequate samples taken (Figure 5). The 
histopathology report revealed $\mathrm{T}$ cell lymphoblastic lymphoma. The patient was treated accordingly.

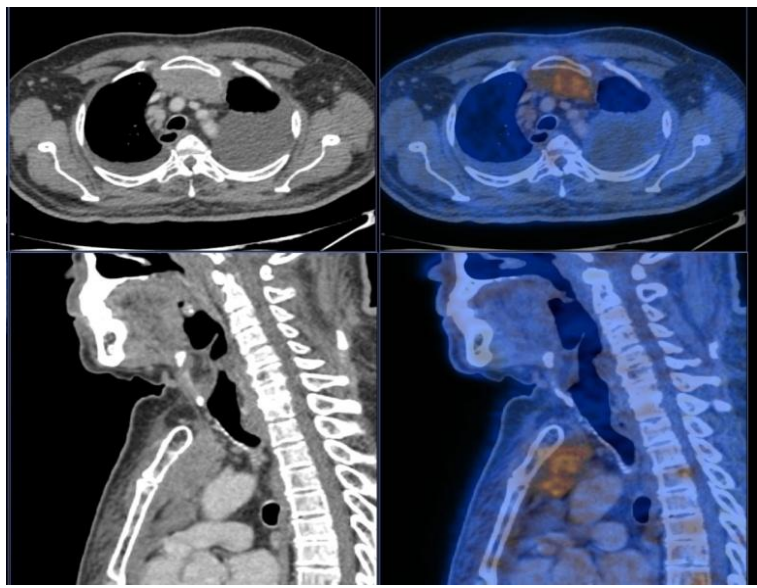

Figure 1: Axial and Coronal PET CT images showing the anterior mediastinal lesion with bilateral pleural effusion (Left side > Right side)

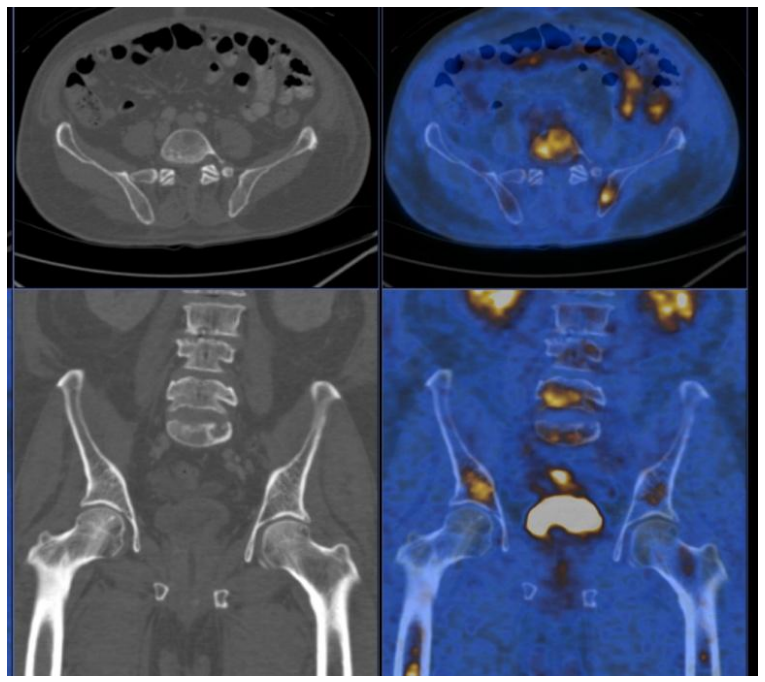

Figure 2: Axial and Sagittal PET CT images showing multiple skeletal metastases.

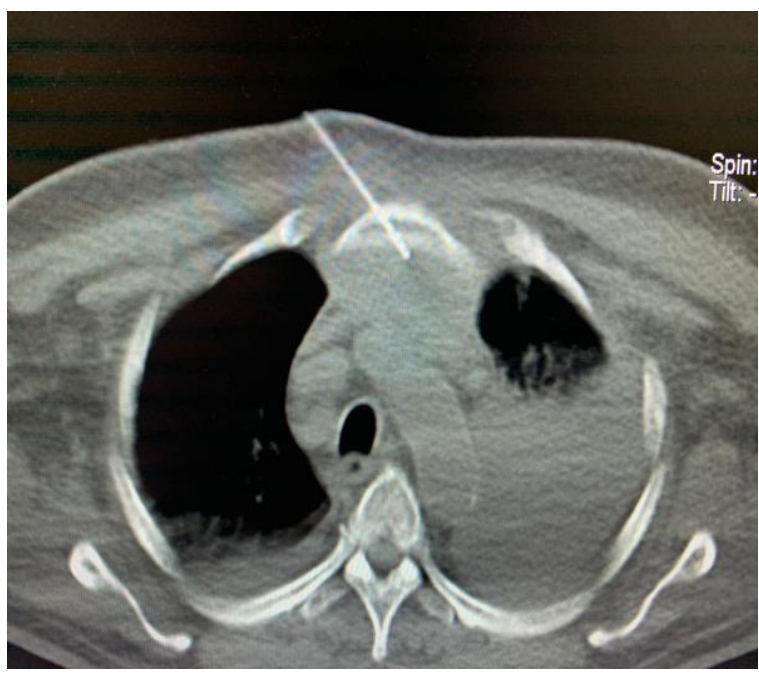

Figure 3: CT scan image showing the transsternal approach for biopsy of anterior mediastinal lesion.

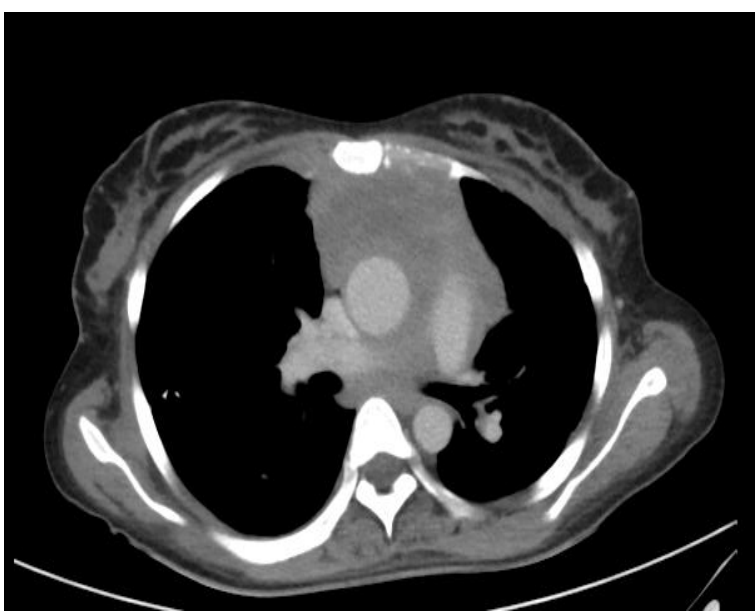

Figure 4: CT scan image showing the soft tissue mass involving anterior mediastinum.

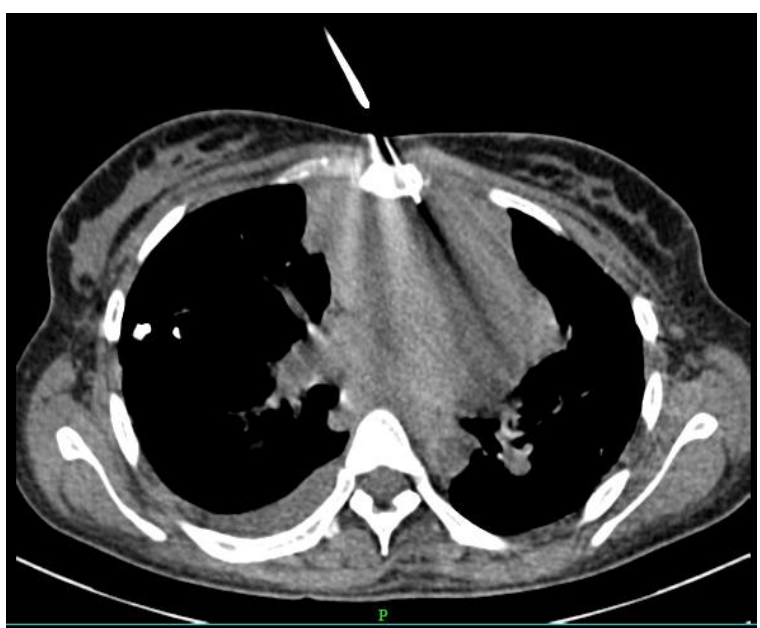

Figure 5: CT scan image showing the transsternal approach for biopsy of anterior mediastinal mass.

\section{DISCUSSION}

Very few cases of CT-guided transsternal mediastinal lesion biopsy have been reported in the literature ${ }^{(\mathbf{1 - 4})}$. Astrom et al (1) reported 10 transsternal biopsies in which he used a bone biopsy system to penetrate the sternum. D'Agostino et al (2) described their early experience for the transsternal approach for biopsy in anterior mediastinal lesions in seven patients and found that procedure is safe, well-tolerated, and effective. Hagberg et al ${ }^{(3)}$ also used the same technique in their recent series involving twenty one patients. Swanson and Wittich ${ }^{(4)}$ reported successful transsternal biopsy in a mediastinal tumor in 1990.

In the earlier days, percutaneous mediastinal lesion biopsy was performed under fluoroscopy guidance. However with the advancement in ultrasound and CT scan 
technology, now-a-days, there is advantage in the form of precise localization and visualization of the biopsy needle and target lesion during the procedure. Ultrasound has role in percutaneous biopsy of para-sternal lesions which are in direct contact with the chest wall or in supra-sternal approach for superior mediastinal lesions. Even after meticulous efforts, the parasternal approach is associated with risk of hemorrhage from injury to internal mammary vessels that traverse along the lateral border of the sternum ${ }^{(5,8)}$. In some cases, it may not be possible to find a safe window between these blood vessels and the sternum. For mediastinal lesions not in direct contact with the parasternal chest wall, angled transpulmonary approach has to be utilised. The reported risk of pneumothorax with this approach ranges from $11 \%$ to $19.2 \%{ }^{(7)}$. We therefore propose CT scan guided transsternal approach for biopsy of mediastinal lesions which have no significant parasternal extension.

The manubrium sternum is a thin bone. Tran-sternal entry into the posteriorly situated anterior mediastinal lesion is safer approach which is well tolerated under proper local anaesthesia (Infiltration of local anaesthetic upto the periosteum of sternum). (7) We recommend coaxial needle insertion of a 17-gauge and biopsy gun of 18-gauge within this needle for biopsy. The risk of complications is negligible because the needle does not traverse the lung or any major structures. The transsternal approach avoids the traversing through lungs, thus reducing the risk of pneumothorax also. Transsternal approach is also helpful for lesions in other mediastinal compartments and in the anterior and medial aspects of the lungs. Middle or posterior mediastinal lesions behind the great vessels in the peritracheal compartments or in the aortopulmonary window can be safely accessible using with transsternal approach. Small-gauge (22- gauge) needles are used to advance between vascular structures to reach these lesions in many of the patients. (7)

\section{CONCLUSION}

CT scan guided trans-sternal anterior mediastinal mass biopsy is safe and easily performable procedure than thought off.

\section{Acknowledgement: None}

\section{Conflict of Interest: None}

\section{Source of Funding: None}

\section{REFERENCES}

1. Astrom KG, Ahlstrom KH, Magnusson A.CT-guided transsternal core biopsy of anterior mediastinal lesions. Radiology 1996; 199:564-567. https://doi.org/10.1148/ radiology.199.2.8668813 PMid:8668813

2. D'Agostino HB, Sanchez RB, Laoide RM, et al. Anterior mediastinal lesions: transsternal biopsy with CT guidance-work in progress. Radiology 1993; 189:703-705. https://doi.org/10.1148/radiology.189.3.823 4694 PMid:8234694

3. Hagberg H, Ahlstrom HK, Magnusson A, Sundstrom C, Astrom GK. Value of transsternal core biopsy in patients with a newly diagnosed mediastinal lesion. Acta Oncol 2000; 39:195-198. https://doi.org/ 10.1080/028418600430761 PMid:10859010

4. Swanson DC, Wittich GR. CT-guided transsternal biopsy of a mediastinal lesion. $\mathrm{J}$ Intervent Radiol 1990; 5:163-164.

5. Glassberg RM, Sussman SK. Lifethreatening hemorrhage due to percutaneous transthoracic intervention: importance of the internal mammary artery. AJR Am J Roentgenol 1990; 154:47-49. https:// doi.org/10.2214/ajr.154.1.2104724 PMid: 2104724

6. Glassberg RM, Sussman SK, Glickstein MF. CT anatomy of internal mammary vessels: importance in planning percutaneous transthoracic procedures. AJR Am J Roentgenol 1990; 155:397-400. https://doi.org/10.2214/ajr.155.2.2115273 PMid:2115273

7. Gupta S, Wallace JM, Morella AF, Jr, Kamran Ahrar K, Hicks EM CT-guided Percutaneous Needle Biopsy of Intrathoracic Lesions by Using the Transsternal Approach: Experience in 37 Patients Vascular and Interventional Radiology, January 2002, Radiology, Vol 222 , No. 1 
8. Cox JE, Chiles C, McMannus CM, Aquino SL, Choplin RH. Transthoracic needle aspiration biopsy: variables that affect risk of pneumothorax. Radiology 1999; 212: 165-168. https://doi.org/10.1148/radiology. 212.1.r99j133165 PMid:10405737
How to cite this article: Bakare VN, Pattnaik S. CT scan guided trans-sternal approach for anterior mediastinal mass biopsy. International Journal of Science \& Healthcare Research. 2021; 6(2): 174-177. DOI: https://doi.org/ 10.52403/ijshr.20210431 